\title{
Psychiatric problems of children exposed to opiates in utero - a descriptive study
}

\author{
Ciaran Clarke, Carol Fitzpatrick
}

Ir J Psych Med 2005; 22(4): 121-123

\section{Abstract}

Objectives: To describe the psychosocial and clinical characteristics of children referred to a community-based child and adolescent mental health service, whose mothers reported that they took opiates during the pregnancy.

Methods: In a retrospective study, the case notes of all children whose mothers reported that they had been exposed to opiates in utero, and who were referred to the Department of Child and Family Psychiatry, Mater Hospital, between 2001-2003, were identified by maternal reports. Information was obtained on age, gender, referral source, socio-economic group, family type, number of siblings, involvement of community care services, nature of presenting problems, diagnosis, interventions offered, and treatment difficulties. Information was recorded anonymously.

Results: 15 children were identified, of whom nine were male. Most were found to be living with their mother alone or with their mother and a partner, and to be socially and financially disadvantaged. Their presenting complaints usually involved combinations of aggressive, hyperactive, and oppositional behaviour. Diagnoses included ADHD, a speech and language disorder, and an axis II disorder. Interventions were frequently unsuccessful because of parents' difficulties with attending appointments, and because of instability in the families' living arrangements.

Conclusions: These children, due to a complex interplay of biological and psychosocial adversity, are at serious risk of ongoing psychiatric disorders in childhood and adolescence, and for adverse outcomes in adult life. A prospective cohort study of all children born to opiatedependent mothers is necessary to quantify the level of risk and identify resilience factors.

Key words: Child psychiatry, Opiates, Pregnancy.

\section{Introduction}

There is surprisingly little information available on long-term outcomes of children exposed to opiates in utero. It is known that some, but not all, such children may suffer from a 'neona-

\footnotetext{
*Ciaran Clarke, MB, MRCPI, MRCPsych, MMedSc, Senior Registrar in Child and Adolescent Psychiatry, Carol Fitzpatrick, MD, FRCPI, MRCPsych, Consultant in Child and Adolescent Psychiatry, Department of Child and Adolescent Psychiatry, Mater Misericordiae Hospital, Eccles Street, Dublin 7, Professor of Child and Adolescent Psychiatry, University College Dublin, Ireland.

${ }^{*}$ Correspondence

SUBMITTED: JANUARY 31, 2005. ACCEPTED: OCTOBER 20, 2005.
}

tal withdrawal syndrome' characterised by irritability, respiratory distress, vague autonomic symptoms, and gastro-intestinal dysfunction. ${ }^{1,2}$ Long-term follow-up studies suggest that children exposed to opiates in utero tend to have cognitive, emotional, and behavioural difficulties and difficulties with regulation of attention and activity. Olofsson et $\mathrm{al}^{3}$ found that only $25 \%$ of opiate-exposed children were physically, mentally, and behaviourally normal at 10 years. Hutchings ${ }^{4}$ found that, whereas cognitive function was normal in such children, symptoms of hyperactivity, impulsivity, and inattention were common. In contrast, a study by Hayes et al, ${ }^{5}$ showed that children reached the age of four or five with few problems. Information on the outcomes of opiate-exposed children might prove helpful in terms of service provision, given the widespread abuse of heroin: recent estimates put the number of heroin abusers in Dublin at $12,000,{ }^{6}$ with women accounting for an ever-increasing proportion of the young people presenting with heroin abuse and dependence. ${ }^{7}$

Children exposed to opiates in utero, in addition to their biological vulnerability associated with opiate exposure in utero, are also exposed to a number of potentially serious psychosocial adversities, which, in their own right, are known to impact on child development. These include attachment difficulties, ${ }^{8,9}$ parental psychiatric disorders, and neglect. Genetic influences may operate as confounders: Men and women with ADHD and conduct disorders are more likely to abuse drugs and also (independently) to have children with the same propensity to hyperactivity and conduct disorders. Few follow-up studies include a control group, making it impossible to disentangle the direct effects of opiate exposure from the psychosocial risk factors.

Almost nothing is known of the long-term development of children born in Ireland to mothers who are opiate-dependent. Neonatal abstinence syndrome is increasingly well recognised and treated, but there are no reports of follow-up extending beyond the first few months of life.

This study is a case series of children referred to the Mater Misericordiae Child and Adolescent Mental Health Service from 2001-2003, in which their mothers reported that they had taken opiates (heroin or methadone) during that pregnancy. There may have been other children referred to the service who were similarly exposed, but whose mothers declined to share this information with us, although questions about pregnancy and neonatal health are routinely included in child mental health assessments.

The study was undertaken to highlight the level of clinical disorder apparent in these children, the difficulties in providing effective interventions, and the likelihood of a poor outcome for actual care. Little attention has been given to this aspect of the burgeoning drug problem in Ireland. 


\section{Methods}

The records of all children attending the Department of Child Psychiatry, Mater Misericordiae Hospital, Dublin, between 2001 and 2003, were reviewed to ascertain, on the basis of maternal reports, whether or not the child's mother had taken intravenous heroin or oral methadone during that pregnancy. Information was collected on each child's age, gender, referral source, socio-economic group, ${ }^{10}$ family type, number of siblings, involvement of community care services, nature of presenting problems, diagnosis, interventions offered and treatment difficulties. The Ethics Committee of the Mater Misericordiae Hospital approved the study.

\section{Results}

Fifteen children were identified who were exposed to opiates in utero, based on maternal reports. Their psychosocial characteristics are shown in Table 1. Most were living with their biological mothers, either alone or with a partner who was not the child's father, and were from disadvantaged socio-economic groups. Community care social work teams were involved because of concerns about level of care of the children in over half the cases. Three children were in foster care. They tended to be referred because of combinations of aggressive and oppositional behaviour, or with hyperactivity and difficulties with attention and concentration. Their diagnoses are shown in Table 2. Five children had more than one diagnosis.

Interventions used included counselling, parent management groups, speech and language therapy and psychopharmacology. Serious difficulties with delivering effective interventions were encountered in 11 cases (inability to attend appointments in five, home-life instability in four, suspected parental misuse of the child's medication in two). Case vignette

Todd, aged three, was referred by the public health nurse, who was concerned about the level of his disturbed behaviour. He had extreme temper tantrums whenever his mother wanted him to do something he did not want to do. He had wandered away from home, been excluded from pre-school because of his aggression to other children, and was hyperactive. He lived with his mother and her partner, having been in foster care from the age of 10 months to 28 months, during which time his mother underwent treatment for opiate dependence. She was currently on maintenance treatment with methadone.

Todd's mother had been dependent on heroin and other drugs throughout her pregnancy, and he had suffered withdrawal symptoms necessitating a four month stay in hospital following his birth.

Todd was a bright child, who showed signs of attachment difficulties with his mother. He was markedly hyperactive, indiscriminately friendly with clinic staff and destructive in his play. Attempts were made to work with Todd's mother and her partner to help them develop a consistent, non-coercive parenting style, but after two sessions they declined further appointments.

Todd was re-referred at eight years of age, when his school felt they could no longer contain his aggressive and risk-taking behaviour. He would regularly leave the school, unaccompanied, and was frequently involved in fights with peers. Despite being of average intellectual ability, he was
Table 1: Psychosocial and demographic characteristics of 15 children exposed to opiates in utero

$\begin{array}{lc}\text { Sex incidence } & \mathbf{n} \\ \text { Male/female } & 9 / 6\end{array}$

Living with

Two biological parents 3

Mother alone 5

Father alone 0

Mother and partner 4

Foster carers 3

Community care social work involvement 9

Presenting complaints*

Aggressive behaviour 5

Temper tantrums 10

Oppositional behaviour 5

Overactive-inattentive 10

Relationship difficulties 12

Anxiety 3

Socio-economic classification ${ }^{10}$

$1-5 \quad 2$

6-8 13

* Multiple complaints were common

\section{Table 2: Diagnoses of 15 children exposed to opiates in utero}

$\begin{array}{ll}\text { Diagnosis* } & \text { n } \\ \text { Attention-deficit hyperactivity disorder } & 5 \\ \begin{array}{l}\text { Conduct disorder/oppositional defiant disorder/ } \\ \text { hyperkinetic conduct disorder }\end{array} & 3 \\ \text { Attachment disorder } & 2 \\ \text { Speech and language disorders } & 3 \\ \text { Other emotional disorders } & 1 \\ \text { No diagnosis but significant impairment } & 5 \\ \text { * Multiple diagnoses were common } & \end{array}$

not learning in school. He was referred to a special school for children with emotional and behavioural problems. His inability to pay attention and his overactivity led to a diagnosis of $A D H D$, and he was treated with methylphenidate, which led to some improvement in his behaviour and concentration. This had to be stopped after four months, as he was regularly coming into school in a dazed 'medicated' state, leading to concerns about overuse of his methylphenidate, and because he didn't attend follow-up appoints to monitor his medication. Todd's mother and her partner subsequently separated because of domestic violence and Todd continues to live with his mother. His breaking into cars has led to garda involvement on a number of occasions. He remains hyperactive, impulsive and aggressive if opposed.

\section{Discussion}

This descriptive study has a number of limitations. It is retrospective and based on clinical descriptions of children we believe were exposed to opiates in utero, based on mater- 
nal reports. The finding cannot be generalised to all children exposed to opiates in utero - there may be many such children who are developing well. The study does not include a control group of children similarly exposed to social adversity but with no exposure to opiates in utero.

In many ways these children do not differ from numerous other children referred to our clinic from areas of high social deprivation. Such children frequently have the same symptom profile and receive the same diagnoses. What makes the children in this study stand out is the severity of their disorders at such a young age, and the inability, despite extensive professional involvement at school, community, and mental health service level, to bring about any significant improvement in their difficulties. Children with hyperactive, aggressive, and oppositional behaviour in early childhood have a poor prognosis, one third becoming persistent juvenile offenders, ${ }^{11}$ at considerable personal cost to themselves, their families and the community.

Aetiologic factors in these children are probably complex. While intra-uterine exposure to opiates does not increase the rates of major congenital anomalies, there is evidence that it causes growth, behaviour, perceptual and learning disabilities, ${ }^{12}$ as well as inattention and hyperactivity. ${ }^{13}$ Opiates may confer a specific vulnerability to ADHD, ${ }^{4}$ much as an association between cocaine and autism has been suggested. ${ }^{14}$ The frequency of attention and hyperactivity in our patients at presentation, as well as their comorbidity are consistent with this, and raise the question as to whether the ADHD of opiate toxicity is different to that of 'common' ADHD in its pathogenesis and response to treatment. People with executive functioning deficits, conduct disorder and ADHD are more likely to develop an opiate addiction..$^{15}$ Young female heroin addicts are strongly influenced in their pattern of drug use by their male partners. ${ }^{16}$ People with addictions demonstrate high rates of personality disorder and comorbid psychiatric illness. Consequently both parents may have genetic risk factors for ADHD, conduct disorder, executive functioning deficits, depressive disorder, etc. Their children may inherit the vulnerability to develop these and other psychiatric problems. There is evidence that a dysfunctional environment may contribute to the cognitive effects of prenatal opiate exposure ${ }^{17}$ Indeed, this may be more important than direct toxicity in determining outcome. ${ }^{18}$

There is some evidence that interventions delivered to opiate dependent parents, with the goal of improving the parenting skills, improve outcomes for their children, ${ }^{19}$ but the difficulties in providing care to these children are formidable. Socioeconomic disadvantage with continued parental substance abuse and other psychiatric problems together may militate against early presentation and regular attendance. Adequate care-giving, while it may ameliorate outcomes in these areas, ${ }^{20}$ does not normalise them. ${ }^{21}$ Even where early intervention is possible, it is difficult to see what form this should take. One fostering study ${ }^{22}$ found that fostering seems to improve outcomes in prenatally exposed children more than in fostered children who have not been exposed to drugs prenatally. Another study found that adoption and fostering improved intellectual function (though not inattention-hyperactivity) in children exposed prenatally to heroin. ${ }^{23}$ Another study, ${ }^{24}$ however, found fostered children to have done worse than those who remained with their natural parents.
Many different services become involved with these children and their parents, often working in a disjointed way, and often unaware of the involvement of other services. These include general practitioners, drug-abuse, obstetric, and paediatric units, and education and community welfare services. Despite (or perhaps because of) this mix of professionals, there is no early intervention programme for these vulnerable children. It is this type of intervention, however, which may make a difference to the long-term outlook for these children.

This study suggests the need for a co-ordinated, prospective, controlled study of children born to opiate-dependent mothers, in order to identify resilience and risk factors, and to set the scene for co-ordination of service provision.

\section{Conclusion}

Children who have been exposed in utero to opiates present severe and complex psychiatric morbidity, and this may be manifest well beyond infancy. Standard service provision does not meet the needs of these children, largely because of social disadvantage and the inabilities of carers. There seems to be a need for better liaison between obstetric, neonatal, addiction, social work, and child psychiatric services to ensure early diagnosis and continuity of care.

\section{Declaration of interest: None}

\section{References}

1. Finnegan LP, Connaughton JF Jr, Kron RE , Emich JP. Neonatal abstinence syndrome: assessment and management. Addict Dis 1975; 2: 141-58.

2. Kaltenbach K, Finnegan LP. Neonatal abstinence syndrome, pharmacotherapy and developmental outcome. Neurobehav Toxicol Teratol 1986; 8: 353-5.

3. Olofsson M, Buckley W, Andersen GE, Friis-Hansen B. Investigation of 89 children born by drug-dependent mothers. II. Follow-up 1-10 years after birth. Acta Paediatr Scand 1983; 72 : drug-depenc.

4. Hutchings DE. Methadone and heroin during pregnancy: a review of behavioral effects in human and animal offspring. Neurobehav Toxicol Teratol 1982; 4: 429-34

5. Hayes JS, Lampart R, Dreher MC, Morgan L. Five-year follow-up of rural Jamaican children whose mothers used marijuana during pregnancy. West Indian Med J 1991; 40: 120-3.

6. Kelly A, Carvalho M, Teljeur C. Prevalence of opiate use in Ireland 2000-2001, 2003.

7. Smyth BP, O'Brien M. Children attending addiction treatment services in Dublin, 1990-1999. Eur Addict Res 2004; 10: 68-74.

8. Goodman G, Hans SL, Cox SM. Attachment behavior and its antecedents in offspring born to methadone-maintained women. Opiate systems in mother and infant primates coordinate intimate contact. J Clin Child Psychol 1999; 28: 58-69.

9. Kalin NH, Shelton SE, Lynn DE. Opiate systems in mother and infant primates co-ordinate intimate contact during reunion. Psychoneuroendocrinology 1995; 20: 735-42.

10. National Statistics - Methods and quality - socio-economic-classification 2003. Available from www.statistics.gov.uk/methods_quality/ns_sec/default.asp

11. Kim-Cohen J, Caspi A, Moffitt TE, Harrington H, Milne BJ, Poulton R. Prior juvenile diagnoses in adults with mental disorder: developmental follow-back of a prospectivelongitudinal cohort. Arch Gen Psychiatry 2003; 60: 709-17.

12. Wilson GS, McCreary R, Kean J, Baxter JC. The development of preschool children of 12. Wilson GS, McCreary R, Kean J, Baxter JC. The development of presch
heroin-addicted mothers: a controlled study. Pediatrics 1979; 63: 135-41.

13. Ornoy A. The effects of alcohol and illicit drugs on the human embryo and fetus. Isr J Psychiatry Relat Sci 2002; 39: 120-32.

14. Davis E, Fennoy I, Laraque D, Kanem N, Brown G, Mitchell J. Autism and developmental abnormalities in children with perinatal cocaine exposure. J Natl Med Assoc 1992; 84: 315-9. 15. Schubiner H, Tzelepis A, Milberger S, Lockhart N, Kruger M, Kelley BJ, Schoener EP. Prevalence of attention-deficit/hyperactivity disorder and conduct disorder among substance abusers. J Clin Psychiatry 2000; 61: 244-51.

16. Eaves CS. Heroin use among female adolescents: the role of partner influence in path of initiation and route of administration. Am J Drug Alcohol Abuse 2004; 30: 21-38.

17. Guo X, Spencer JW, Suess PE, Hickey JE, Better WE, Herning RI. Cognitive brain potential alterations in boys exposed to opiates: in utero and lifestyle comparisons. Addict Behav 1994; 19: 429-41.

18. Ornoy A, Michailevskaya V, Lukashov I, Bar-Hamburger R, Harel S. The developmental outcome of children born to heroin-dependent mothers, raised at home or adopted. Child Abuse Negl 1996; 20: 385-96.

19. Dawe S, Harnett PH, Rendalls V, Staiger P. Improving family functioning and child outcome in methadone maintained families: the Parents Under Pressure programme. Drug Alcohol Rev in methadone maintain 22 : 299-307.

2003; 22: 299-307.
20. Johnson HL, Glassman MB, Fiks KB, Rosen TS. Resilient children: individual differences in developmental outcome of children born to drug abusers. J Genet Psychol 1990; 151: 523-39. 21. Moe V. Foster-placed and adopted children exposed in utero to opiates and other substances: prediction and outcome at four and a half years. J Dev Behav Pediatr 2002; 23: 330-9.

22. McNichol T, Tash C. Parental substance abuse and the development of children in family foster care. Child Welfare 2001; 80: 239-56.

23. Ornoy A. The impact of intrauterine exposure versus postnatal environment in neurodevelopmental toxicity: long-term neurobehavioral studies in children at risk for developmental disorders. Toxicol Lett 2003; 140-141: 171-81.

24. Soepatmi S. Developmental outcomes of children of mothers dependent on heroin or heroin/methadone during pregnancy. Acta Paediatr Suppl 1994; 404: 36-9. 